\title{
Use of blends of bioabsorbable poly(L-lactic acid)/poly(hydroxybutyrate- co-hydroxyvalerate) as surfaces for Vero cell culture
}

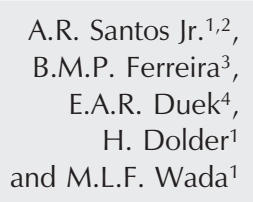

A.R. Santos Jr. ${ }^{1,2}$

B.M.P. Ferreira ${ }^{3}$,

E.A.R. Duek,

H. Dolder ${ }^{1}$

and M.L.F. Wada ${ }^{1}$

\author{
${ }^{1}$ Departamento de Biologia Celular, Instituto de Biologia, \\ Universidade Estadual de Campinas, Campinas, SP, Brasil \\ ${ }^{2}$ Instituto de Ciências Biológicas, Centro Regional Universitário de Espírito Santo \\ do Pinhal, Espírito Santo do Pinhal, SP, Brasil \\ ${ }^{3}$ Departamento de Engenharia de Materiais, Faculdade de Engenharia Mecânica, \\ UNICAMP, Campinas, SP, Brasil \\ ${ }^{4}$ Departamento de Ciências Fisiológicas, Faculdade de Ciências Biológicas, \\ Pontifícia Universidade Católica de São Paulo, Sorocaba, SP, Brasil
}

\author{
Correspondence \\ A.R. Santos Jr. \\ Departamento de Biologia Celular \\ Instituto de Biologia, UNICAMP \\ Caixa Postal 6109 \\ 13084-971 Campinas, SP \\ Brasil \\ Fax: +55-19-3788-6111 \\ E-mail: arsantosjr@yahoo.com.br
}

Research supported by CNPq, FINEP-PRONEX, and FAPESP

(No. 97/14275-7).

Received January 10, 2004 Accepted May 20, 2005

\begin{abstract}
Vero cells, a cell line established from the kidney of the African green monkey (Cercopithecus aethiops), were cultured in F-10 Ham medium supplemented with $10 \%$ fetal calf serum at $37^{\circ} \mathrm{C}$ on membranes of poly(L-lactic acid) (PLLA), poly(hydroxybutyrate-co-hydroxyvalerate) (PHBV) and their blends in different proportions (100/0, 60/40, 50/50, $40 / 60$, and $0 / 100$ ). The present study evaluated morphology of cells grown on different polymeric substrates after $24 \mathrm{~h}$ of culture by scanning electron microscopy. Cell adhesion was also analyzed after $2 \mathrm{~h}$ of inoculation. For cell growth evaluation, the cells were maintained in culture for 48, 120, 240, and $360 \mathrm{~h}$. For cytochemical study, the cells were cultured for 120 or $240 \mathrm{~h}$, fixed, processed for histological analysis, and stained with Toluidine blue, $\mathrm{pH} 4.0$, and Xylidine ponceau, $\mathrm{pH} 2.5$. Our results showed that cell adhesion was better when $60 / 40$ and 50/50 blends were used although cells were able to grow and proliferate on all blends tested. When using PLLA/PHBV (50/50) slightly flattened cells were observed on porous and smooth areas. PLLA/PHBV (40/60) blends presented flattened cells on smooth areas. PLLA/PHBV (0/100), which presented no pores, also supported spreading cells interconnected by thin filaments. Histological sections showed that cells grew as a confluent monolayer on different substrates. Cytochemical analysis showed basophilic cells, indicating a large amount of RNA and proteins. Hence, we detected changes in cell morphology induced by alterations in blend proportions. This suggests that the cells changed their differentiation pattern when on various PLLA/PHBV blend surfaces.
\end{abstract}

Key words

- Poly(L-lactic acid)

- Poly(hydroxybutyrate-

co-hydroxyvalerate)

- Blends

- Biomaterials

- Cell culture

- Vero cells 


\section{Introduction}

A research area that has recently received increased attention is tissue engineering, in which functional tissue is restored from native or synthetic sources by using engineering principles. Biomaterials play an important role working as scaffolds to guide tissue regeneration, releasing drugs and growth factors to stimulate tissue response, or creating a new functional structure when damaged tissue does not regenerate (1-3). In this context, a clear understanding of cell responses to the biomaterial used is needed. This information would permit the use of biomaterials and cell culture techniques to create tissue-like structures that simulate the mechanical and physiological characteristics of tissues in vivo. These devices could be also produced for healing manipulation and to stimulate natural tissue regeneration.

In many cases, depending on the regenerative capacity of damaged tissues, the use of biodegradable materials is clinically recommended. In such situations, there is only a need for the temporary presence of biomaterials to provide support to the damaged area, or substitute it, so as to direct the growth and restoration of tissues (4). A wide variety of bioabsorbable polymers have been used in biological systems, and polyesters derived from $\alpha$-hydroxy acids are those most frequently employed (5).

Bioabsorbable polymers slowly degrade after implantation. This feature may be important for many tissue regeneration applications, since the polymer will disappear as functional tissue restoration occurs. Poly(Llactic acid) (PLLA) is a biodegradable polyester that has been used experimentally as a support for cell culture or experimental treatment of some damaged tissues mainly due to its high biocompatibility. Applications of this polymer have been studied in our laboratory (6-8). Poly(hydroxybutyrate-co-hydroxyvalerate) (PHBV) is also a biodegradable polyester produced by microorganisms.
The biocompatibility of PHBV has been studied (9) and the material has also been investigated for the improvement of blood vessel restoration (10).

Cell culture is a very important tool for the study of biomaterials. It provides a quick and reliable pre-selection method so as to choose the best sample that will later be tested in animals. Testing in animals is very expensive and hinders viewing the direct effects of biomaterials on the stimulation of important parameters such as cell proliferation, growth and differentiation. Thus, our objective in the present study was to evaluate the biological interactivity of blends of PLLA/PHBV, with respect to their capacity to modify cell adhesion and growth in vitro.

\section{Material and Methods}

\section{Preparation of PLLA/PHBV blends}

PLLA/PHBV blends were produced in the Department of Material Engineering, Mechanical Engineering College, UNICAMP. Briefly, the blends were prepared by dissolving PLLA (Medisorb Technologies, Cincinnati, OH, USA), molecular weight = 100,000, and PHBV (Aldrich, Milwaukee, WI, USA), molecular weight $=240,000$. The blends were prepared by dissolving the polymers separately in 5\% methylene chloride $(w / v)$ under stirring for approximately $1 \mathrm{~h}$. The final composition of PLLA/PHBV blends were 100/0, 60/40, 50/50, 40/60, and $0 / 100$, which were stirred for $1 \mathrm{~h}$ for complete homogenization. The PLLA/PHBV mixture was poured onto glass plate. The glass containing the blend in solution was placed in a glass box to dry. After evaporation of the solvent, membranes, with approximately $0.14 \mathrm{~mm}$ thick, were obtained and washed with demineralized water for $48 \mathrm{~h}$. The membranes were maintained under vacuum, following the drying phase. For cell culture experiments, PLLA/PHBV blends were sterilized overnight in $70 \%$ etha- 
nol and the sterility of the samples was tested. The samples were washed three times in F-10 Ham medium (Sigma, St. Louis, MO, USA) and then incubated in the same culture medium for $24 \mathrm{~h}$ at $37^{\circ} \mathrm{C}$ before cell inoculation.

\section{Cell culture}

Vero cells, a cell line established from the kidney of the African green monkey (Cercopithecus aethiops), were obtained from the Adolfo Lutz Institute, São Paulo, SP, Brazil. Cells were cultured in F-10 Ham medium (Sigma) supplemented with $10 \%$ fetal calf serum (FCS, Nutricell Nutrientes Celulares, Campinas, SP, Brazil) at $37^{\circ} \mathrm{C}$. Vero cells are recommended for studies of cytotoxicity and for cell-substrate interactions with biomaterials $(11,12)$. The culture medium was replaced whenever had the acidification of it. Before inoculation, the cells were maintained in culture flasks of 25 or $50 \mathrm{ml}$ with a surface area of 25 or $50 \mathrm{~cm}^{2}$, respectively (Corning, Cambridge, MA, USA).

\section{Cell adhesion assay}

The method of Mosmann (13) with some modifications, was used for the cell adhesion assay. Briefly, the sterilized PLLA/ PHBV blends $(\mathrm{N}=6)$ were placed in a 96well plate with $32 \mathrm{~mm}^{2}$ of surface area (Corning) with $100 \mu \mathrm{l}$ of culture medium and kept at $37^{\circ} \mathrm{C}$ for $24 \mathrm{~h}$. After incubation, $1.0 \times 10^{6}$ cells/ml in $100 \mu \mathrm{F}-10$ Ham medium supplemented with $10 \%$ FCS were added to the wells containing the substrates. The cells were cultured for $2 \mathrm{~h}$ in F-10 Ham supplemented with $10 \% \mathrm{FCS}$ at $37^{\circ} \mathrm{C}$, washed twice with $0.1 \mathrm{M}$ phosphate-buffered saline (PBS), $\mathrm{pH} 7.4$, at $37^{\circ} \mathrm{C}$ and incubated with $100 \mu \mathrm{F}$ 10 Ham medium.

The assay mixture $(10 \mu$ l per well $)$ containing $5 \mathrm{mg} / \mathrm{ml}$ of 3-(4,5-dimethylthiazol-2-yl)2,5-diphenyl-tetrazolium bromide (MTT, Sigma) was added to each well and incubated for $4 \mathrm{~h}$ at $37^{\circ} \mathrm{C}$. After $4 \mathrm{~h}, 100 \mu \mathrm{l}$ isopropanol acid (Isofar Ind., Jacaré, RJ, Brazil) was added to each well and, after $3 \mathrm{~h}$, was quantified spectrophotometrically based on absorbance at $540 \mathrm{~nm}$, using a Bio-Rad Model 550 microplate reader (Bio-Rad Laboratories Inc., Hercules, CA, USA). The MTT is an incolor salt of tetrazolium that, when oxidized by mitochondria, form a dark composed detected by spectrophotometry. The measurements are proportional to cell number (13). Cells on the culture plate itself (polypropylene) without other substrates and silicone membranes were used as positive and negative controls, respectively. We also read the absorbance of all experimental conditions (different PLLA/ PHBV blends, negative or positive controls) without cells for control of the MTT reaction. The statistical significance $(\mathrm{P}<0.05)$ was assessed using one-way analysis of variance (ANOVA) followed by Tukey HSD multiple comparison test.

\section{Cell growth on PLLA/PHBV blends}

For the cell proliferation assay we used a modification of the method described by Murakami et al. (14). Briefly, the PLLA/PHBV blends $(\mathrm{N}=9)$ were added to a 96-well plate with F-10 Ham medium for $24 \mathrm{~h}$ at $37^{\circ} \mathrm{C}$. After incubation, $1.0 \times 10^{3}$ cells $/ \mathrm{ml}$ in $200 \mu \mathrm{F}-10$ Ham medium supplemented with $10 \%$ FCS were added to the PLLA/PHBV blends. The cultures were maintained for 48, 120, 240, and $360 \mathrm{~h}$, washed with $0.1 \mathrm{M}$ PBS, pH 7.4, at $37^{\circ} \mathrm{C}$, fixed in $10 \%$ formalin for $15 \mathrm{~min}$, washed in PBS, and stained with $0.05 \%$ crystal violet (in 20\% methanol) for $15 \mathrm{~min}$. The samples were then washed twice with $0.1 \mathrm{M}$ PBS and incubated with $0.1 \mathrm{M}$ sodium citrate in $50 \%$ ethanol, $\mathrm{pH} 4.2$, for $30 \mathrm{~min}$. The wells were read with a Multiskan Bichromatic Version 1.06 microplate reader (Labsystems Inc., Helsinki, Finland) at 540-nm wavelength. The culture plate itself (polypropylene) was used as a positive control and Teflon membranes were used as a negative control. We also read the absorbance of all experimental conditions 
(PLLA/PHBV blends, negative/positive controls) in a cell-free condition for dye staining control.

\section{Scanning electron microscopy}

The three-dimensional blends of different compositions were fractured by immersion in liquid nitrogen, covered with gold using a sputter coater (Baltec SCD 050, Fursteintum Liechtenstein, Germany) and observed with a JEOL JXA-840 (Jeol Co., Tokyo, Japan) scanning electron microscope. For the analysis of cell morphology, $1.0 \mathrm{x}$ $10^{5}$ cells $/ \mathrm{ml}$ were inoculated into different PLLA/PHBV blends in 24-well culture plates (with $2 \mathrm{~cm}^{2}$ of surface area; Corning) in F-10 Ham medium with $10 \%$ FCS. Cells cultured on a glass coverslip under the same culture conditions were used as control. After $24 \mathrm{~h}$, the samples were fixed in $3 \%$ glutaraldehyde (Sigma) in $0.1 \mathrm{M}$ phosphate buffer, $\mathrm{pH}$ 7.2 , for $45 \mathrm{~min}$ at $4^{\circ} \mathrm{C}$, and postfixed with $1 \%$ $\mathrm{OsO}_{4}$ (Sigma) for $2 \mathrm{~h}$ at $4^{\circ} \mathrm{C}$. The specimens were then dehydrated in graded ethanol se- ries, critical point dried (Balzers CDT 030, Balzers Inc., Elgin, IL, USA) and coated with gold in a sputter coater. The coated specimens were observed and photographed with a JEOL JSM-5800 scanning electron microscope.

\section{Cytochemical analysis}

For cytochemical study, $1.0 \times 10^{5}$ cells/ $\mathrm{ml}$ were cultured on membranes prepared with the different PLLA/PHBV blends in F10 Ham medium supplemented with $10 \%$ FCS. After 48, 120, and $240 \mathrm{~h}$ in culture, the samples were fixed with Karnovsky fixative (4\% paraformaldehyde $2.5 \%$ glutaraldehyde in $0.2 \mathrm{M}$ phosphate buffer, $\mathrm{pH}$ 7.2), dehydrated in graded ethanol series at room temperature, cleared in xylene, and embedded in paraplast. Sections of $5 \mu \mathrm{m}$ were obtained with a microtome (Reicher-Jung, New York, NY, USA) with a steel knife (Leica Instruments, Nussloch, Germany) and stained with Toluidine blue (TB), $\mathrm{pH} 4.0$, a basophilic dye, for the detection of DNA, RNA and
Figure 1. Morphology and electron micrographs of PLLA/PHBV blends. A, Structure of PLLA and PHBV. Figures B-F show scanning electron microscopy of membranes prepared from PLLA, PHBV and mixtures of these components: $B$, PLLA/ PHBV (100/0) blend; C, PLLA/ PHBV (60/40) blend; $D$, PLLA/ PHBV (50/50) blend; $E$, PLLA/ PHBV (40/60) blend; $F$, PLLA/ PHBV $(0 / 100)$ blend. Scale bar: $100 \mu \mathrm{m}$. PLLA $=$ poly $($ L-lactic acid); PHBV = poly (hydroxybutyrate-co-hydroxyvalerate).

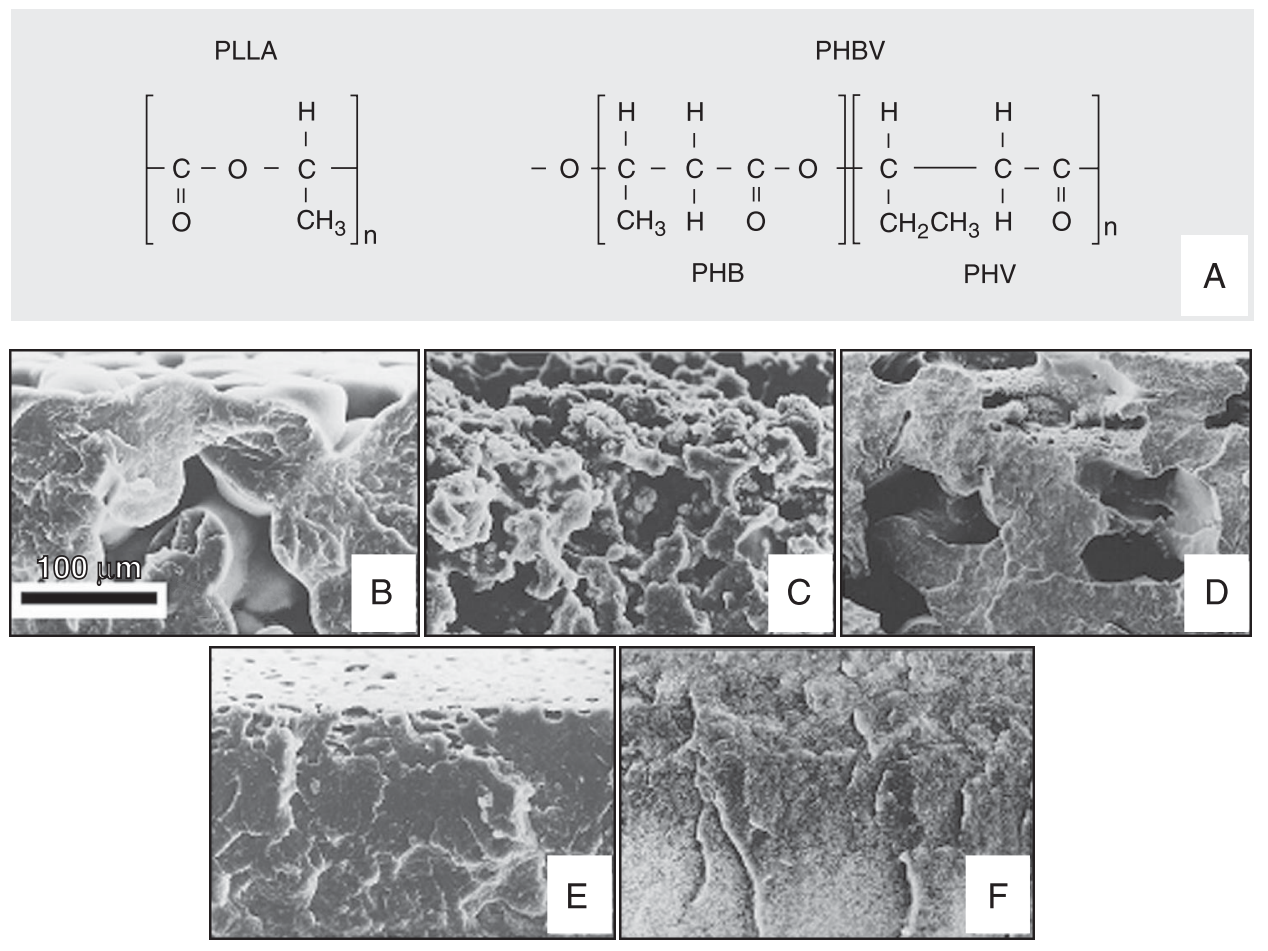


glycosaminoglycans, with Alcian blue, $\mathrm{pH}$ 2.5, a basophilic dye, for the detection of glycosaminoglycans, and with Xylidine ponceau (XP), $\mathrm{pH} 2.5$, an anionic dye, for the identification of cationic proteins (1517). Staining time was $15 \mathrm{~min}$ for TB and 20 min for XP, both at room temperature. The coverslips obtained were photographed under an inverted IX-50 Olympus microscope (Tokyo, Japan) and figures were prepared using Adobe Photoshop software.

\section{Results}

\section{PLLA/PHBV substrates}

The molecular structure and electron micrographs of PLLA, PHBV and the PLLA/ PHBV blends used in the present experiment were shown in Figure 1.

\section{Cell adhesion}

All membranes presented a low capacity to stimulate cell adhesion compared with the positive control used $(\mathrm{P}<0.05)$. The PLLA/ PHBV blends (100/0, 40/60 and 0/100) showed a cell adhesion capacity similar to that of the negative control. Only the 60/40 and 50/50 PLLA/PHBV blends proved to be more receptive to cell interaction $(\mathrm{P}<0.05)$. These results are illustrated in Figure 2A.

\section{Growth curve on different PLLA/PHBV blends}

All samples showed a higher mitotic cell rate than the negative control. It is interesting to note that the pure polymers used (100/ 0 and $0 / 100$ ) showed a similar proliferative rate, whereas $60 / 40$ and $40 / 60$ blends showed a lower proliferative index. In all cases, cells grew slower than the positive control. However, in long-term cultures there was a decrease in cell number for the positive control, suggesting the senescence of the cell layer. This behavior was not observed in the different PLLA/PHBV blends (Figure 2B).

\section{Scanning electron microscopy}

Figure 1A shows the molecular structure of PLLA and PHBV, as well as electron micrographs obtained by scanning electron
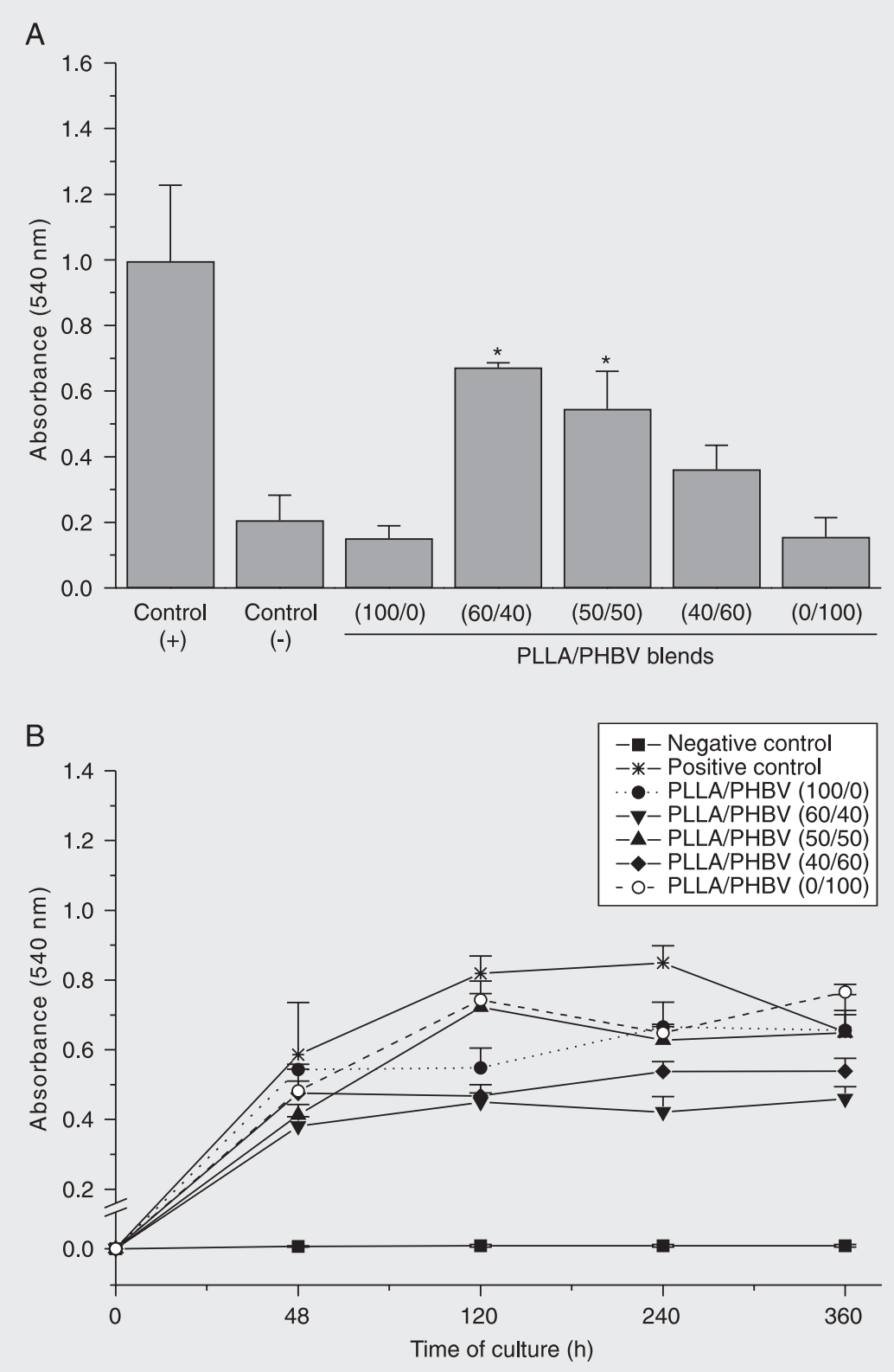

Figure 2. A, Adhesion of Vero cells cultured to different PLLA/PHBV blends. All samples studied displayed the capacity to stimulate less adhesion than the positive control. The (100/0), (40/60) and (0/100) blends were not different from the negative control. ${ }^{*} P<0.05$ compared to negative control (Tukey multiple comparison test). $B$, Growth curve of Vero cells cultured on different PLLA/PHBV blends. In all samples, the cells grew slower than the positive control. PLLA = poly(L-lactic acid); PHBV = poly(hydroxybutyrate-cohydroxyvalerate). 

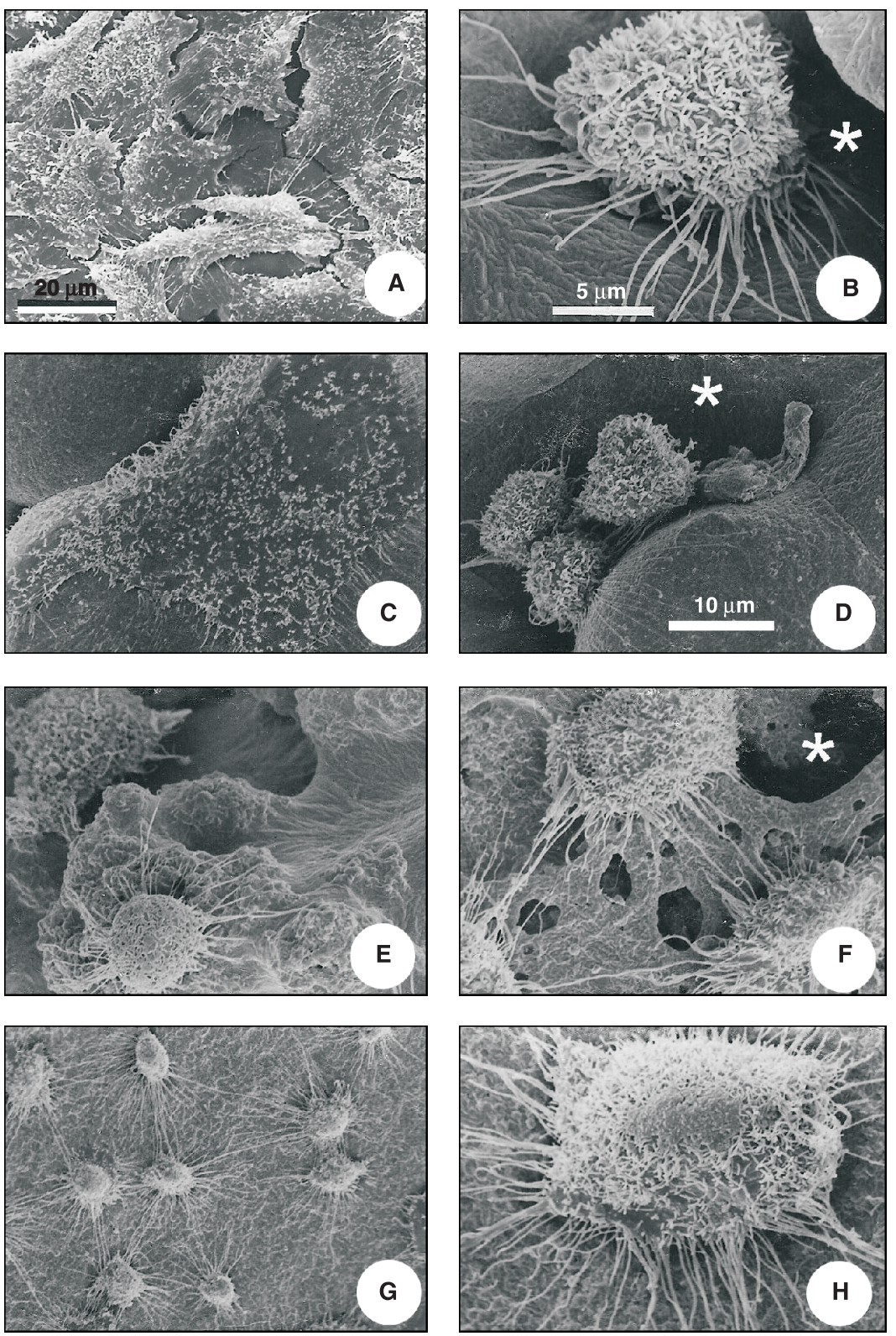

Figure 3. Scanning electron microscopy of Vero cells cultured on the polymers for $24 \mathrm{~h}$. $A$, Cells cultured on a glass coverslip. The cells are either elongated or flattened. B, PLLA/ PHBV (100/0) membrane with round cells growing in a pore, with microvilli and thin filaments. $C$, A non-porous region of the same polymer. In this area, the cells are flattened. $D$, Cells on a $(60 / 40)$ PLLA/PHBV blend. Cells had a growth pattern similar to that of the previous samples, although in the porous regions they were more irregular in structure. $E$, Cells on a (50/50) PLLA/PHBV blend. Flattened cells with filaments grow in similar proportions on porous or non-porous areas. $F$, Cells on a (40/60) PLLA/PHBV blend. Flattened cells showed shrinkage at their edges and grew preferably on non-porous areas. G) Cells on a (0/100) PLLA/PHBV membrane. In this case, we found thin filaments linking the cells. $H$, Sample showing a flattened cell on a (0/100) PLLA/PHBV membrane at high magnification. In the figures, the porous area is represented by asterisk. Scale bar: $20 \mu \mathrm{m}$ for figures $\mathrm{A}$ and $\mathrm{G}, 5 \mu \mathrm{m}$ for $\mathrm{B}, \mathrm{C}$ and $\mathrm{H}$, and $10 \mu \mathrm{m}$ for other figures. PLLA = poly(L-lactic acid); PHBV $=$ poly (hydroxybutyrate-co-hydroxyvalerate). microscopy of fractured blend surfaces. PLLA/PHBV (100/0) membranes were porous, with a rounded structure (Figure 1B). The decreased concentration of PLLA in the blends, such as 60/40 and 50/50 samples, results in alterations of porosity (Figure 1C and D, respectively). PLLA/PHBV (40/60) shows that the blend acquired a dense structure, with the presence of cavities on the surface (Figure 1E). PLLA/PHBV (0/100) was completely dense as verified by its fracture (Figure 1F). In the scanning electron microscopy of cells cultured on the glass coverslip we could see the formation of a non-confluent cell layer. The cells showed irregular morphology, with a flattened and elongated shape (Figure 3A). In the PLLA/ PHBV (100/0) blends we found cells growing on porous or non-porous areas. In the pores, the cells were round, with microvilli on their surface. They also showed numerous long and thin filaments budding from the basal portion of the cell (Figure 3B). On the other hand, on the same membranes, the cells that grew on non-porous areas were flattened on the substrate surface (Figure 3C). In the PLLA/PHBV (60/40) blends we found cells with a growth pattern very similar to that of the former samples, although the pores seen in blends were more irregular (Figure 3D). In PLLA/PHBV (50/50), in contrast to the previous samples, surfaces were irregular, with cells producing many thin filaments (Figure 3E). The PLLA/PHBV (40/60) blends displayed flattened cells, which were shrunk along their edges (Figure 3F). In PLLA/PHBV (0/100) samples, which do not present pores, we found flat or round cells with many interconnecting thin filaments (Figure 3G,H).

\section{Cytochemical analysis}

During the culture period cells were able to reach confluence on the substrate and to migrate into different PLLA/PHBV blends through the pores on the blend surface. In all 
samples, at different time, we detected cells strongly stained by $\mathrm{TB}$ or XP, which are basophilic and acidophilic dyes, respectively. We did not find cytochemical alterations induced by the different PLLA/PHBV membranes on which the cells were cultured (Figure 4). All samples were negative for Alcian blue at pH 2.5 (data not shown).

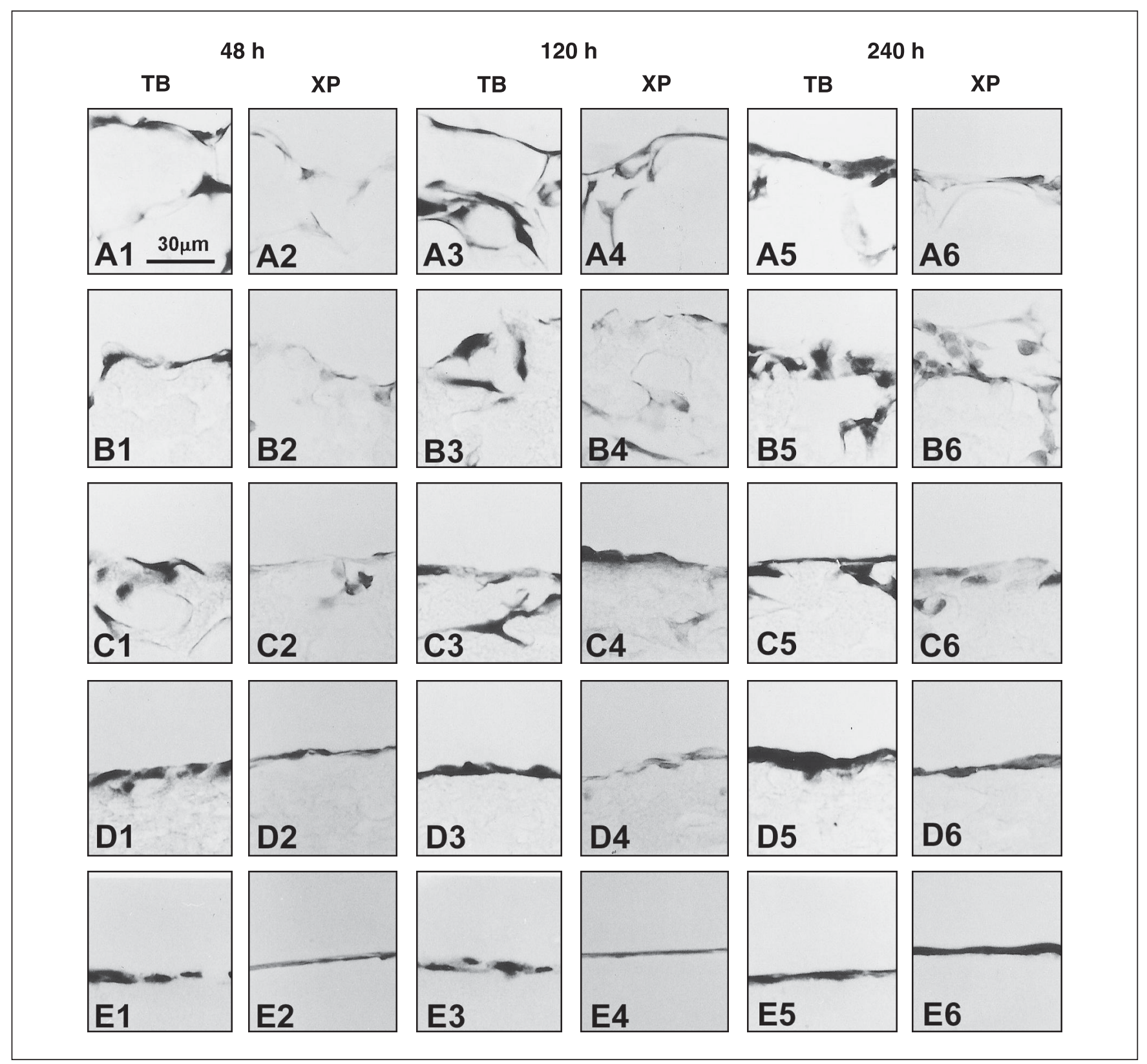

Figure 4. Vero cells cultured on different PLLA/PHBV blends for 48, 120, and $240 \mathrm{~h}$ and stained with Toluidine blue (TB) or Xylidine ponceau (XP). A, Cells cultured on PLLA/PHBV (100/0) blends. B, Cells cultured on PLLA/PHBV (60/40) blends. C, Cells cultured on PLLA/PHBV (50/50) blends. D, Cells cultured on PLLA/PHBV and (40/60) blends. E, Cells cultured on PLLA/PHBV (0/100) blends. From A1 to E1, A3 to E3 and A5 to E5 the samples were stained with $\mathrm{TB}, \mathrm{pH}$ 4.0. From $\mathrm{A} 2$ to $\mathrm{E} 2, \mathrm{~A} 4$ to $\mathrm{E} 4$ and $\mathrm{A} 6$ to $\mathrm{E} 6$ the cells were stained with $\mathrm{XP}, \mathrm{pH} 2.5$. In all samples and at all culture time points we found basophilic (TB) or acidophilic (XP) cells growing on the surface of different polymers. We could also observe that on a porous substrate the cells were able to migrate into the polymeric scaffold. We did not find indications of cytochemical alterations induced by the different proportions of blend composition. Scale bar: $30 \mu \mathrm{m}$ for all figures. PLLA = poly(L-lactic acid); PHBV = poly(hydroxybutyrate-co-hydroxyvalerate). 


\section{Discussion}

In this study, we observed variations in cell morphology induced by the physicochemical characteristics of the membranes upon which they were cultured. In homopolymers, PLLA/PHBV (100/0) or (0/100), rounded or flattened cells were observed. In porous areas of PLLA/PHBV (100/0) or (60/ 40) cells were flat, possibly because of the effects of surface tension. The physicochemical properties of different materials could modulate cell morphology and behavior. Signaling from polymers that drive the cell growth pattern is complex and may originate from dipole and electric charge interaction forces, hydrogen bonds, electrostatic forces, hydrophilicity/hydrophobicity or surface free energy, and roughness and rigidity, surface tension, and substrate topography (18-20). The morphology of Vero cells on pure PLLA scaffolds observed here was similar to previous results obtained by our group $(7,8,21)$, which showed that round or spreading cells attached on PLLA surface by thin cytoplasmatic filaments. Each new form of production of biomaterial can bring variations in its structure and porosity. All these characteristics can be sensed by the cells that react to them by changing its morphology. The reproducibility of the cell morphological results indicates a good standardization of polymer production, a desirable characteristic to development of biomaterials for clinical utilization.

The cell morphology of PLLA/PHBV had not been previously described. In a recent study on long-term cultures, Köse et al. (22), reported that osteoblastic cells cultured on PHBV scaffolds had a spread or polygonal morphology with extended filopodia similar to that observed for some blends in the present study. Thus, the signaling from PHBV that drives osteoblast growth may be similar to that observed here for fibroblastic cells.

The occurrence of pores on a biomaterial surface can also modulate the cell proliferation rate. Pores represent an increased area for cell growth and division. In vivo, the pore structure is a desirable characteristic that could create a three-dimensional environment for tissue growth, increasing the tissuepolymer interaction. In vitro, PLLA devices have been used to support the growth and proliferation of endothelial cells without stimulating platelet activation (23). It is interesting to note that in our proliferation assay we observed a similar multiplication rate on homopolymers, PLLA/PHBV (100/ 0 or 0/100), compared with the PLLA/PHBV $50 / 50$ blend. It was recently reported that mouse NIH/3T3 fibroblasts cultured on PHBV showed a satisfactory adhesion and proliferation rate and that this property was increased with a physicochemical modification of the PHBV surface that increased the hydrophilicity of the polymer (24). In another report PHBV sustained cell proliferation rates similar to that observed in collagen sponges for at least 35 days of culture (25). Thus, our results obtained for PLLA/PHBV blends agree with those reported for pure PHBV and indicate that our blends are good scaffolds for cell culture.

We found that the cells were able to proliferate until convergence on all PLLA/ PHBV blends. They were also able to enter into pores, creating three-dimensional arrangements on the blend surface, even on those samples where cell affinity for the pores was smaller. The uniform distribution and interconnection of porous structures are important for cell migration and the formation of organized network structures similar to a tissue (26). A similar growth pattern of Vero cells on different polymers was previously reported. We found the formation of a cell monolayer on compact or porous PLLA membranes (8), on poly(2-hydroxy ethyl methacrylate) polymers (poly-HEMA) (21), on a blend of poly-HEMA with acrylic acid (poly-HEMA-co-AA) (27), and on a blend of poly-HEMA-poly(MMA-co-AA) (28). In 
addition, we observed Vero cell multilayers growing on dry collagen I sponges (29) or on collagen I gels in short- (30) or long-term (31) culture studies.

Cytochemistry has not shown alterations in cell behavior induced by different PLLA/ PHBV blend proportions. In all samples, we found basophilic cells stained by TB that, in $\mathrm{pH} 4.0$, can stain nucleic acids and glycosaminoglycans. Although Vero cells can synthesize glycosaminoglycans (32), they produce these molecules in a soluble form in the culture medium. Thus, the basophilic cytoplasm suggests that cells are able to active protein synthesis. The XP, that can stain proteic groups, confirms these results. A similar cytochemical pattern was found in Vero cells cultured on other biomaterials such as poly-HEMA hydrogels $(27,28)$ or collagen I (31). These results agree with the description that different cells are able to produce extracellular matrix on PHBV poly- mers $(33,34)$.

Due to an intense search for better biomaterials over the last years, clinical applications of reabsorbable polymers have been increasing. Several studies have been carried out to search for biomaterials that could help in the repair of articular cartilage and bones $(3,35)$. In a recent study, PHBV was implanted in the tibia of rabbits as an antibiotic carrier, with no significant symptoms of chronic inflammation or toxicity observed (36). The results described in the present study show promising results for the biological use of PLLA/PHBV. Usually blends present advantageous physical and mechanical properties if compared to pure polymers. Our results demonstrate that PLLA/PHBV have the desirable characteristics for use in bioimplants. By changing the blend proportion, apparently the cells respond by changing their differentiation pattern.

\section{References}

1. Langer R \& Vacanti JP (1993). Tissue engineering. Science, 260: 920-926.

2. Hench LL (1998). Biomaterials: a forecast for the future. Biomaterials, 19: 1419-1423.

3. An YH, Woolf SK \& Friedman RJ (2000). Pre-clinical in vivo evaluation of orthopaedic bioabsorbable devices. Biomaterials, 21: 26352652.

4. Hubbell JA (1995). Biomaterials in tissue engineering. Biotechnology, 13: 565-576.

5. Törmälä $P$, Pohjonen $T$ \& Rokkanen $P$ (1998). Bioabsorbable polymers: materials technology and surgical applications. Proceedings of the Institution of Mechanical Engineers Part H, Journal of Engineering in Medicine, 212: 101-111.

6. Barbanti SH, Zavaglia CAC \& Duek EAR (2002). Porous and dense poly(L-lactic acid) membranes: in vitro degradation. Acta Microscopica, 11: 85-89.

7. Zoppi RA, Contant S, Duek EAR et al. (1999). Porous poly(L-lactide) films obtained by immersion precipitation process: morphology, phase separation and culture of VERO cells. Polymer, 40: 32753289.

8. Santos Jr AR, Barbanti SH, Duek EAR et al. (2001). Growth and differentiation of Vero cells on poly(L-lactic acid) membranes of different pore diameters. Artificial Organs, 25: 7-13.

9. Baran ET, Özer N \& Hasirci V (2002). Poly(3-hydroxybutirate-co3hydroxyvalerate) nanocapsules as enzyme carriers for cancer therapy: an in vivo study. Journal of Microencapsulation, 19: 363376.
10. Peng T, Gibula P, Yao KD et al. (1996). Role of polymer in improving the results of stenting in coronary arteries. Biomaterials, 17: 685694.

11. International Standart (1992). Biological evaluation of medical devices - Part 5. Tests for cytotoxicity: in vitro methods. ISO 10993-5, 1992(E).

12. Kirkpatrick CJ (1992). Biological testing of materials and medical devices - A critical view of current and proposed methodologies for biocompatibility testing: cytotoxicity in vitro. Regulatory Affairs, 4: 13-32.

13. Mosmann T (1983). A rapid colorimetric assay of cellular growth and survival: application to proliferation and cytotoxicity assays. Journal of Immunological Methods, 65: 55-63.

14. Murakami N, Fukuchi S, Takeuchi K et al. (1998). Antagonistic regulation of cell migration by epidermal growth factor and glucocorticoid in human gastric carcinoma cells. Journal of Cellular Physiology, 176: 127-137.

15. Lison L (1960). Histochemie et Cytochemie Animales - Principles et Methodes. Gauthier Villars, Paris, France.

16. Módis L (1991). Organization of the Extracellular Matrix: A Polarization Microscopy Approach. CRC Press, Boca Raton, FL, USA.

17. Mello MLS (1997). Cytochemistry of DNA, RNA and nuclear proteins. Brazilian Journal of Genetics, 20: 257-264.

18. Lee JH, Lee JW, Khang $\mathrm{G}$ et al. (1997). Interaction of cells on chargeable functional group gradient surfaces. Biomaterials, 18: 351-358.

19. Pelham RJ \& Wang YL (1997). Cell locomotion and focal adhesion 
are regulated by substrate flexibility. Proceedings of the National Academy of Sciences, USA, 94: 13661-13665.

20. Dalby MJ, Childs S, Riehle MO et al. (2003). Fibroblast reaction to island topography: changes in cytoskeleton and morphology with time. Biomaterials, 24: 927-935.

21. Lombello CB, Santos Jr AR, Malmonge SM et al. (2002). Adhesion and morphology of fibroblastic cells cultured on different polymeric biomaterials. Journal of Material Science. Materials in Medicine, 13: 867-874.

22. Köse GT, Kenar H, Hasirci N et al. (2003). Macroporous poly(3hydroxybutyrate-co-3-hydroxyvalerate) matrices for bone tissue engineering. Biomaterials, 24: 1949-1958.

23. Hsu SH, Tseng HJ \& Fang ZH (1999). Polyurethane blended with polylactides for improved cell adhesion and reduced platelet activation. Artificial Organs, 23: 958-961.

24. Lee SJ, Lee YM, Khang G et al. (2002). Effect of poly(3-hydroxybutyrate-co-hydroxyvalerate) surface with different wettability on fibroblast behavior. Macromolecular Research, 10: 150-157.

25. Rivard CH, Chaput C, Rhalmi S et al. (1996). Bio-absorbable synthetic polyesters and tissue regeneration. A study of three-dimensional proliferation of ovine chondrocytes and osteoblasts. Annales de Chirurgie, 50: 651-658.

26. Wald HL, Sarakinos G, Lyman MD et al. (1993). Cell seeding in porous transplantation devices. Biomaterials, 14: 270-278.

27. Lombello CB, Malmonge SM \& Wada MLF (2000). Morphology of fibroblastic cells cultured on poly(HEMA-co-AA) substrates. Cytobios, 101: 115-122.

28. Lombello CB, Malmonge SM \& Wada MLF (2000). PolyHEMA and
poly-HEMA-poly(MMA-co-AA) as substrates for culturing Vero cells. Journal of Material Science. Materials in Medicine, 11: 541-546.

29. Wada MLF \& Vidal BC (1991). Growth and differentiation of Vero cells cultivated in three-dimensional type I collagen. Cytobios, 67: 101-109.

30. Santos Jr AR, Dolder H \& Wada MLF (2003). Effects of fetal calf serum and dexamethasone in the differentiation of fibroblastic cells cultured on collagen I gel. Journal of Submicroscopic Cytology and Pathology, 35: 35-42.

31. Maria SS \& Wada MLF (1997). Cytochemical analysis of Vero cells on type I collagen gels in long-term culture. In Vitro Cellular and Developmental Biology. Animal, 33: 748-750.

32. Stabellini G, Calastrini C, Scapoli L et al. (2002). The effect of polyamines and dialysate fluid on extracellular matrix synthesis in VERO cell cultures. Journal of Nephrology, 15: 539-546.

33. Deng Y, Lin X-S, Zheng Z et al. (2003). Poly(hydroxybutyrate-cohydroxyhexanoate) promoted production of extracellular matrix of articular cartilage chondrocytes in vitro. Biomaterials, 24: 42734281.

34. Santos Jr AR, Ferreira BMP, Duek EAR et al. (2004). Differentiation pattern of Vero cells cultured on poly(I-lactic acid)/poly(hydroxybutyrate-co-hydroxyvalerate) blends. Artificial Organs, 28: 381-389.

35. Temenoff JS \& Mikos AG (2000). Review: tissue engineering for regeneration of articular cartilage. Biomaterials, 21: 431-440.

36. Gürsel I, Korkusuz F, Türesin F et al. (2001). In vivo application of biodegradable controlled antibiotic release systems for the treatment of implant-related osteomyelitis. Biomaterials, 22: 73-80. 